\title{
The Renin-Angiotensin System in Conscious Newborn Sheep: Metabolic Clearance Rate and Activity
}

\author{
SITHEMBISO C. VELAPHI, KEVIN DESPAIN, TIMOTHY ROY, AND CHARLES R. ROSENFELD \\ Department of Pediatrics, Division of Neonatal-Perinatal Medicine, University of Texas Southwestern Medical Center at Dallas, \\ Dallas, Texas 75390-9063
}

\begin{abstract}
The role of the renin-angiotensin system (RAS) in regulating newborn mean arterial blood pressure (MAP) and tissue blood flow remains unclear. Although postnatal MAP increases, vascular responsiveness to infused angiotensin II (ANG II) is unchanged, possibly reflecting increased metabolic clearance rate of ANG II ( $\mathrm{MCR}_{\mathrm{ANG} \text { II }}$ ). To address this, we examined MAP, heart rate, plasma ANG II and renin activity (PRA), and $\mathrm{MCR}_{\mathrm{ANG}}$ in conscious postnatal sheep ( $n=9,5-35 \mathrm{~d}$ old) before and during continuous systemic ANG II infusions to measure $\mathrm{MCR}_{\mathrm{ANG}}$.I Postnatal MAP increased $(p<0.02)$, whereas plasma ANG II decreased from $942 \pm$ $230(\mathrm{SEM})$ to $471 \pm 152$ and $240 \pm 70 \mathrm{pg} / \mathrm{mL}$ at $<10 \mathrm{~d}, 10-20 \mathrm{~d}$, and $21-35 \mathrm{~d}$ postnatally $(p=0.05$ ), respectively. Despite high plasma ANG II, PRA remained elevated, averaging $6.70 \pm 1.1$ $\mathrm{ng} / \mathrm{mL} \cdot \mathrm{h}$ throughout the postnatal period, but decreased $35 \%(p=$ 0.01 ) during ANG II infusions. $\mathrm{MCR}_{\mathrm{ANG} \text { II }}$ decreased approximately sixfold after birth and averaged $115 \mathrm{~mL} / \mathrm{min} \cdot \mathrm{kg}$ during the first month. Circulating ANG II is markedly increased after birth, reflecting placental removal, high fetal $\mathrm{MCR}_{\mathrm{ANG}}$ II and enhanced RAS activity. Although circulating ANG II decreases as MAP increases, $\mathrm{MCR}_{\text {ANG II }}$ is unchanged, suggesting decreased ANG II production. Persistent vascular smooth muscle (VSM) $\mathrm{AT}_{2}$ receptor subtype $\left(\mathrm{AT}_{2} \mathrm{R}\right)$ expression after birth may modify the hypertensive effects of ANG II postnatally. (Pediatr Res 61: 681-686, 2007)
\end{abstract}

$\mathrm{T}$ he RAS has been considered an important modulator of cardiovascular changes during the perinatal period (1-4). ANG II, the predominant vasoactive agent associated with the RAS, is believed to contribute to the regulation of basal and stress-induced changes in blood flow and blood pressure in fetal, neonatal, and adult sheep (3-6). It mediates its actions by binding to specific ANG II receptors (ATRs). In adults, including sheep, the $\mathrm{AT}_{1}$ receptor subtype $\left(\mathrm{AT}_{1} \mathrm{R}\right)$ is the primary receptor expressed in most tissues and mediates the majority of biologic responses to ANG II, including its effects on VSM and arterial pressure $(7,8)$. However, $\mathrm{AT}_{2} \mathrm{R}$, which does not mediate vasoconstriction, is the predominant receptor in fetal tissues, including the peripheral VSM, and persists in the postnatal period $(7,9-11)$. In newborn sheep, the transition from the $\mathrm{AT}_{2} \mathrm{R}$ to $\mathrm{AT}_{1} \mathrm{R}$ in VSM begins $2-4$ wk after birth and is not complete until $3 \mathrm{mo}(9,10)$. Although the definitive roles

Received September 11, 2006; accepted January 19, 2007.

Correspondence: Charles R. Rosenfeld, M.D., UT Southwestern Medical Center at Dallas, 5323 Harry Hines Blvd., Dallas, TX 75390-9063; e-mail: charles.rosenfeld@ utsouthwestern.edu

These studies were supported in part by the George L. MacGregor Professorship in Pediatrics and National Institutes of Health grant HD-08783.

DOI: $10.1203 /$ pdr.0b013e3180534252 of the VSM AT $\mathrm{AT}_{2} \mathrm{R}$ during development are unclear (7), it does not mediate vasoconstrictor responses, but may contribute to the regulation of VSM maturation (12-14) and/or the attenuation of $\mathrm{AT}_{1} \mathrm{R}$-mediated responses by the $\operatorname{VSM}(7,15,16)$.

Basal MAP increases during the first month of life in neonates of several species (17-20), but vascular responses to systemic ANG II infusions are unchanged $(17,21)$. Unlike an $\alpha$-agonist or arginine vasopressin (AVP), arterial ANG II infusions in the hind limb of conscious newborn sheep do not elicit changes in blood flow or peripheral vascular resistance (PVR), suggesting that it does not directly alter PVR $(17,18)$. Therefore, the absence of an increase in vascular reactivity or sensitivity to infused ANG II with increasing postnatal age could be due to persistent $\mathrm{AT}_{2} \mathrm{R}$ expression in peripheral VSM during the first postnatal month $(9,10)$ or the stage of VSM functional maturation (22). Alternatively, the $\mathrm{MCR}_{\mathrm{ANG}}$ II may increase with increasing postnatal age, resulting in an apparent attenuation of the responses to systemic ANG II infusions. For example, the pressor responses to comparable doses of infused ANG II by fetal sheep were reported to be attenuated compared with those of adult animals (23). However, we (24) subsequently reported that these attenuated fetal pressor responses were due to a fetal $\mathrm{MCR}_{\mathrm{ANG} \text { II }}$ that was more than ninefold higher than the adult. Thus, when pressor responses were examined at comparable plasma levels of ANG II, there was no difference in fetal and maternal responses to infused ANG II. It is unclear whether the absence of an increase in the pressor responsiveness to infused ANG II in the first postnatal month is also due to alterations in $\mathrm{MCR}_{\mathrm{ANG}}$.I. Furthermore, the activity of the RAS has not been well characterized in the newborn of any species. The present study was designed to examine and characterize the relationships between basal MAP, arterial levels of ANG II and PRA, and the $\mathrm{MCR}_{\mathrm{ANGI}}$ in conscious, chronically instrumented newborn sheep during the first 5 wk postnatally.

\section{MATERIALS AND METHODS}

Animal preparation. Nine newborn singleton sheep (five males, four females) were studied between 5 and $35 \mathrm{~d}$ postnatally. The animal preparation has been described $(17,18)$. Briefly, after delivery at our facility, surgery was

\footnotetext{
Abbreviations: ANG II, angiotensin II; $\mathbf{M C R}_{\mathrm{ANG} \mathrm{II}}$, angiotensin II metabolic clearance rate; $\mathbf{A T}_{\mathbf{2}} \mathbf{R}, \mathrm{AT}_{2}$ receptor subtype; $\mathbf{A T}_{\mathbf{1}} \mathbf{R}, \mathrm{AT}_{1}$ receptor subtype; PRA, plasma renin activity; PVR, peripheral vascular resistance; RAS, reninangiotensin system
} 
performed at 2-5 d of life. Preoperatively, animals received subcutaneous (s.c.) atropine $(0.088 \mathrm{mg} / \mathrm{kg}$ ) followed by intravenous (i.v.) sodium pentobarbital $(7.5-10 \mathrm{mg} / \mathrm{kg})$ and $1 \%$ ketamine hydrochloride $(1-2 \mathrm{mg} / \mathrm{kg})$ via a percutaneous jugular venous catheter. During surgery, $1 \%$ ketamine hydrochloride ( $1 \mathrm{mg} / \mathrm{kg}$ i.v.) was given to maintain deep anesthesia. Through an inguinal incision in one hind limb, the femoral artery and vein were identified, dissected, and two polyvinyl catheters containing heparinized saline (250 $\mathrm{U} / \mathrm{mL}$ ) were implanted at 12.5 and $7.5 \mathrm{~cm}$ in the femoral artery for cardiovascular monitoring and blood sampling. A femoral venous catheter was inserted at $15 \mathrm{~cm}$, placing the tip above the bifurcation of the inferior vena cava, and used for systemic ANG II infusions. The catheters were flushed with heparinized saline $(250 \mathrm{U} / \mathrm{mL})$, closed with sterile metal pins, brought out to the flank through an s.c. tunnel, and placed in a canvas pouch attached to the skin with sterile steel pins. The skin incisions were closed with surgical staples. During surgery, animals received $10 \%$ dextrose and isotonic saline at $20 \mathrm{~mL} / \mathrm{kg} \cdot \mathrm{h}$ to maintain plasma glucose and volume. All animals received i.v. banamine $(0.1 \mathrm{~mL}$; Schering-Plough Animal Health, Union, NJ) for pain and intramuscular penicillin $(60,000 \mathrm{U})$ and gentamicin $(7.5 \mathrm{mg})$ for prophylaxis after surgery and the next $2 \mathrm{~d}$ postoperatively. After surgery, animals received $70 \mathrm{~mL} / \mathrm{kg}$ of $5 \%$ dextrose and isotonic saline over $4 \mathrm{~h}$ and were maintained under a heated warmer until they recovered from anesthesia. They were returned to their mothers for feeding, but were removed the first night and kept in a recovery facility in the Animal Resources Center for monitoring and bottle feeding. Subsequently, each animal was kept with its mother except during an experiment. Catheters were flushed daily with heparinized saline $(250 \mathrm{U} / \mathrm{mL})$ to maintain patency. All animals received prophylactic intramuscular penicillin $(60,000 \mathrm{U})$ and gentamicin $(7.5 \mathrm{mg})$ at the completion of each study. These studies were approved by the Institutional Animal Care and Use Committee at University of Texas Southwestern Medical Center.

Experimental protocol. Studies were performed after the animals were considered to have recovered from surgery and were eating; no animal was studied before the second postoperative day. Studies were performed in a sling after a 40-min control period and demonstrating stable hemodynamic parameters and arterial blood gases $(17,18)$. Two doses of ANG II (angiotensin amide, Sigma Chemical Co., St. Louis, MO), 0.573 and $1.15 \mu \mathrm{g} / \mathrm{min}$ that had previously been studied in our laboratory were selected for these studies $(11,23)$. However, because each animal was growing and would weigh differently at the time of each study, doses were changed to 0.076 and 0.19 $\mu \mathrm{g} / \mathrm{kg} \cdot \mathrm{min}$ to account for expected growth and change in the volume of distribution. The use of two doses permitted us to determine whether the $\mathrm{MCR}_{\mathrm{ANG}}$ II was dose related. After the stabilization period, ANG II was infused via the femoral venous catheter using a constant infusion pump (Harvard Apparatus, S. Natick, MA). The order of doses was randomly chosen, and infusions were maintained for $20 \mathrm{~min}$ while MAP and heart rate were continuously monitored. Blood samples $(3 \mathrm{~mL})$ for measurements of plasma ANG II and/or PRA were obtained from the femoral arterial catheter after stabilization, before beginning the ANG II infusion (control) and at 5, 10, 15, and 20 min during the 20-min infusion. MAP and heart rate were continuously monitored with pressure transducers (P23XL, Gould, Cleveland, $\mathrm{OH}$ ), and the signals recorded on an eight-channel recorder (model RS 3800, Gould Corp.) and PONEMAH Data Acquisition System (Gould Corp.).

ANG II assay. When the femoral arterial catheter was patent, blood samples $(3 \mathrm{~mL})$ were collected as described above. Additional arterial samples were taken from an adult nonpregnant ewe to assess recovery and compare with previous levels from our laboratories (25). Blood samples were collected in chilled syringes, placed in chilled tubes containing ethylenediamine tetraacetic acid and 1,10-phenanthroline (monohydrate) (Sigma Chemical Co.-Aldrich, St. Louis, MO), centrifuged at $1200 \mathrm{rpm}$ at $4^{\circ} \mathrm{C}$ for $15 \mathrm{~min}$, and the plasma removed and placed in $75 \times 12$-mm polystyrene tubes. The plasma was stored at $-20^{\circ} \mathrm{C}$. To determine recovery, one set of maternal plasma samples was prepared unmodified, and a second and third set had 200 or $1000 \mathrm{pg} / \mathrm{mL}$ of ANG II added before freezing. At the time of assay, plasma samples were thawed and the extraction procedure outlined in the enzyme immunoassay kit (Peninsula Laboratories, Inc., San Carlos, CA) was used; however, we substituted the C18 columns with $100 \mathrm{mg}$ phenyl columns (Varian, Harbor City, CA). After extraction, the eluant was collected in $1.5-\mathrm{mL}$ microcentrifuge tubes, placed in an integrated Speedvac system ISS110 (Savant Instruments, Inc., Farmingdale, NY) to evaporate to dryness, and reconstituted using assay buffer. Samples were read in a microplate reader (Bio-tek Instruments, Inc., Winooski, VT) at $450 \mathrm{~nm}$. The intra-assay and interassay variability were $3.59 \%$ and $11 \%$, respectively. Recovery was $>80 \%$.

$\boldsymbol{M C R}_{\text {ANG Ir }}$ The $\mathrm{MCR}_{\mathrm{ANG} \mathrm{II}}$ was calculated as previously described (24-27). This assumes that the endogenous production rate of ANG II is small compared with the rate of ANG II infusion and a steady state has been achieved. When this occurs, the MCR is calculated with the following equation: $\mathrm{MCR}_{\mathrm{ANG} \mathrm{II}}=\mathrm{I} / \mathrm{C}_{\mathrm{p}} \cdot \mathrm{W}$, where $\mathrm{MCR}_{\mathrm{ANG} \text { II }}$ is ANG II clearance in
$\mathrm{mL} / \mathrm{min} \cdot \mathrm{kg}$ body weight, $\mathrm{C}_{\mathrm{p}}$ is the ANG II plasma concentration in the steady state in $\mathrm{pg} / \mathrm{mL}$, I is the rate of ANG II infusion in $\mathrm{ng} / \mathrm{min}$, and W is the weight in $\mathrm{kg}$ at each study. $\mathrm{MCR}_{\mathrm{ANG}}$ II was calculated at 15 and $20 \mathrm{~min}$ of infusion.

$\boldsymbol{P R A}$. PRA was measured as ANG I generation with a commercial kit (RIANEN, New England Nuclear, North Billerica, MA) and is expressed as nanograms of ANG I formed per milliliter of plasma per hour. The use and accuracy of this assay in our laboratories have been reported (28).

Statistical analyses. Linear and nonlinear regression analyses were used to examine changes over time or with a dose of ANG II. Analysis of variance (ANOVA) for multiple groups was used to compare data grouped by postnatal age followed by the appropriate post hoc test. In this instance, studies were grouped as $<10 \mathrm{~d}, 10-20 \mathrm{~d}$, and $21-35 \mathrm{~d}$ postnatally; however, the $\mathrm{n}$ values presented will differ based on the data analyzed. For example, although there were 17 studies of MCR in nine animals, two doses were examined in four experiments on the same day and baseline data cannot be counted twice. Therefore, in four experiments, the preinfusion values were averaged, resulting in 13 values for basal ANG II, MAP, and heart rate. Also note that two samples were not available for PRA measurements. $p$ Values are presented for each analysis. Data are presented as the means \pm SEM.

\section{RESULTS}

Baseline parameters. Basal MAP increased during the postnatal study period (Table $1 ; p=0.015$ by ANOVA), increasing $14 \%$ at $1 \mathrm{mo}$, whereas heart rate decreased $24 \%$ $(p=0.06)$. Arterial blood gases obtained before infusion of each ANG II dose at each age were within normal ranges for our laboratory and similar between age groups. Although MAP increased during the first month, basal arterial levels of ANG II progressively decreased (Fig. 1), decreasing from $942 \pm 230 \mathrm{pg} / \mathrm{mL}(n=3)$ at $<10 \mathrm{~d}$ postnatally to $471 \pm 152(n=6)$ and $240 \pm 70(n=4) \mathrm{pg} / \mathrm{mL}$ at $10-20 \mathrm{~d}$ and 21-35 d ( $p=0.05$, ANOVA), respectively. In contrast, basal

Table 1. Physiologic parameters before the systemic infusion of ANG II in conscious newborn sheep

\begin{tabular}{lccc}
\hline & $<10 \mathrm{~d}$ & $10-20 \mathrm{~d}$ & $21-35 \mathrm{~d}$ \\
\hline No. of animals & 3 & 6 & 4 \\
MAP (mm Hg) & $74 \pm 1.2$ & $79 \pm 1.7$ & $84 \pm 2.4^{*}$ \\
Heart rate (beats/min) & $198 \pm 18$ & $191 \pm 9.1$ & $150 \pm 11 \dagger$ \\
Arterial blood gases & & & \\
$\quad \mathrm{pH}$ & $7.40 \pm 0.02$ & $7.44 \pm 0.01$ & $7.44 \pm 0.01$ \\
$\mathrm{pco}_{2}$ & $38 \pm 0.4$ & $35 \pm 1.3$ & $37 \pm 0.8$ \\
$\mathrm{po}_{2}$ & $78 \pm 3.5$ & $92 \pm 3.8$ & $84 \pm 6.3$ \\
\hline
\end{tabular}

Data are mean \pm SEM.

$* p<0.02 ; \dagger p=0.06$ (both by ANOVA).



Figure 1. Baseline levels of arterial angiotensin II in conscious newborn sheep during the first postnatal month. Values are grouped by age: $<10 \mathrm{~d}$ $(n=3), 10-20 \mathrm{~d}(n=6)$, and $>20 \mathrm{~d}(n=4) \cdot p=0.05$, ANOVA. 
Table 2. MAP, heart rate, and arterial plasma levels of ANG II in conscious newborn sheep before and during the systemic infusions of ANG II in the first month of life

\begin{tabular}{|c|c|c|c|c|c|}
\hline & $\begin{array}{l}\text { Dose of ANG II } \\
(\mu \mathrm{g} / \mathrm{min} \cdot \mathrm{kg})\end{array}$ & $n$ & Control & $15 \mathrm{~min}$ & $20 \mathrm{~min}$ \\
\hline \multicolumn{6}{|c|}{ MAP $(\mathrm{mm} \mathrm{Hg})$} \\
\hline$<10 \mathrm{~d}$ & 0.076 & 2 & $74 \pm 1.2$ & $87 \pm 6.8$ & $87 \pm 6.8$ \\
\hline \multirow[t]{2}{*}{$10-20 \mathrm{~d}$} & 0.076 & 4 & $78 \pm 0.8$ & $100 \pm 2.3$ & $100 \pm 2.3$ \\
\hline & 0.191 & 3 & $80 \pm 3.5$ & $110 \pm 4.8$ & $110 \pm 4.8$ \\
\hline $21-35 d$ & 0.076 & 4 & $85 \pm 5.0$ & $118 \pm 2.0$ & $118 \pm 2.0$ \\
\hline \multirow[t]{2}{*}{$<10 \mathrm{~d}$} & 0.076 & 2 & $211 \pm 9.0$ & $165 \pm 24$ & $165 \pm 24$ \\
\hline & 0.191 & 2 & $180 \pm 50$ & $140 \pm 60$ & $140 \pm 60$ \\
\hline \multirow[t]{2}{*}{$10-20 \mathrm{~d}$} & 0.076 & 4 & $183 \pm 14$ & $133 \pm 11$ & $133 \pm 11$ \\
\hline & 0.191 & 3 & $200 \pm 12$ & $135 \pm 12$ & $135 \pm 12$ \\
\hline \multirow[t]{2}{*}{$21-35 \mathrm{~d}$} & 0.076 & 4 & $138 \pm 8$ & $103 \pm 13$ & $103 \pm 13$ \\
\hline & 0.191 & 2 & $162 \pm 18$ & $116 \pm 4$ & $116 \pm 4$ \\
\hline $10-20 \mathrm{~d}$ & 0.191 & 3 & $531 \pm 214$ & $1332 \pm 383$ & $1240 \pm 374$ \\
\hline \multirow{2}{*}{$21-35 d$} & 0.076 & 4 & $305 \pm 67$ & $1051 \pm 107$ & $1015 \pm 125$ \\
\hline & 0.191 & 2 & $125 \pm 21$ & $1563 \pm 802$ & $1556 \pm 711$ \\
\hline
\end{tabular}

Data are mean \pm SEM.

PRA was increased and unchanged throughout the first postnatal month $(r=0.03, p=0.92)$, averaging $6.70 \pm 1.1$ $\mathrm{ng} / \mathrm{mL} \cdot \mathrm{h}$.

Cardiovascular responses to infused ANG II. At each age, the measurements of basal MAP and heart rate did not differ before infusion of either dose of ANG II (Table 2). As anticipated (17), systemic infusions of ANG II increased MAP dose dependently $(p=0.019)$ at each age. Steady-state pressor responses were achieved within $2 \mathrm{~min}$ and remained unchanged throughout the 20-min infusion $(p>0.1$, ANOVA). There was no increase in the relative MAP responses, i.e. the percent rise, with increasing postnatal age, demonstrating that the responsiveness to ANG II was unchanged. Heart rate decreased during ANG II infusions, and similar to MAP, achieved a steady-state response that was unchanged during the continuous infusions.

ANG II metabolic clearance. To measure the MCR of any substance, the rate of infusion should exceed the endogenous production rate, and a steady-state plasma level of the substance must be achieved (24-27). Arterial levels of ANG II achieved steady-state levels within 5 min (data not shown) of initiating the systemic ANG II infusion with each dose and at each age studied ( $p=0.007$, ANOVA), except for 0.191 $\mu \mathrm{g} / \mathrm{min} \cdot \mathrm{kg}$ at $<10 \mathrm{~d}$, and a steady-state arterial concentration was maintained at 15 and 20 min during all studies (Table 2). When we compared the $\mathrm{MCR}_{\mathrm{ANG}}$ II obtained with the two primary doses studied, values were $80 \%$ higher with 0.191 versus $0.076 \mu \mathrm{g} / \mathrm{min} \cdot \mathrm{kg}, 145 \pm 23(n=6)$ versus $81.3 \pm 7.1$ $(n=8) \mathrm{mL} / \mathrm{min} \cdot \mathrm{kg}(p=0.01)$. This dose-dependent response in $\mathrm{MCR}_{\mathrm{ANG} \text { II }}$ was also observed when measurements at other rates of infusion were included in the analysis (Fig. 2; $r=$ $0.95, p<0.001, n=17)$. There was, however, no relationship between postnatal age and $\mathrm{MCR}_{\mathrm{ANG} \mathrm{II}}$ (Fig. $3 ; r=0.32, p=$
$0.2, n=17)$ with either rate of infusion. There also was no relationship between basal ANG II levels and $\mathrm{MCR}_{\mathrm{ANG} \mathrm{II}}$ (data not shown, $p>0.1$ ).

Because the arterial levels of PRA remained increased throughout the study period, despite increased levels of circulating ANG II, it was unclear whether the negative feedback mechanism of ANG II on PRA was intact. Therefore, we examined simultaneous concentrations of ANG II and PRA at 15 and 20 min of infusion. At both times, the increase in ANG II was associated with a reciprocal decrease in PRA, e.g. at 15 min ANG II increased $160 \%$, and PRA decreased 35\% from $6.93 \pm 1.2$ to $4.47 \pm 0.86$ (Fig. $4, p<0.01$ ).

\section{DISCUSSION}

During the transition from the fetal to neonatal state, there is an increase in MAP associated with removal of the low



Figure 2. Relationship between MCR ANG II and rate of ANG II infusion in conscious newborn sheep $(n=17)$. 


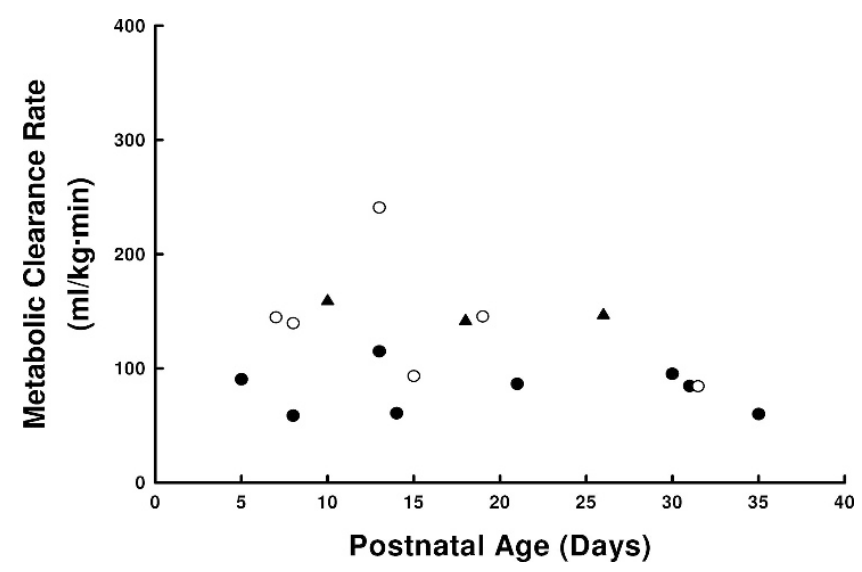

Figure 3. Relationship between $\mathrm{MCR}_{\mathrm{ANG} \mathrm{II}}$ and postnatal age in conscious newborn sheep. Open circles represent $\mathrm{MCR}_{\mathrm{ANG}}$ II at infusion rate of 0.076 $\mu \mathrm{g} / \mathrm{kg} \cdot \min (n=8)$, filled circles at $0.191 \mu \mathrm{g} / \mathrm{kg} \cdot \min (n=6)$ and filled triangles with other doses $(n=3)$.
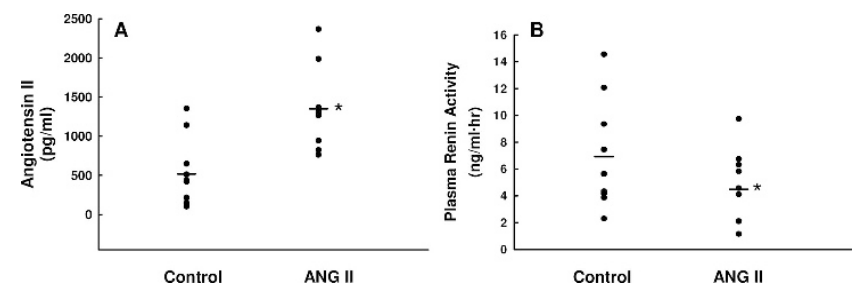

Figure 4. Relationship between arterial plasma ANG II $(A)$ and PRA (B) before and at 15 min of ANG II infusion in conscious newborn sheep $(n=$ 10). Horizontal lines represent means. ${ }^{*} p \leq 0.004$.

resistance placental vascular bed and increased circulating levels of ANG II, catecholamines, and AVP (1,29-31). Basal MAP increases further during the next 2-4 wk (17-20). The contributions of the RAS to the increase in MAP at birth and subsequent weeks are unclear. In term newborn sheep, the $\mathrm{AT}_{2} \mathrm{R}$, which does not mediate vasoconstriction, persists in peripheral VSM until $>4$ wk postnatally (9). Although infused ANG II increases MAP, vascular sensitivity is unchanged and PVR is unaffected $(17,21)$. The constant vascular sensitivity could reflect an increased $\mathrm{MCR}_{\mathrm{ANG}}$ in the newborn, which has not been studied, resulting in the rapid removal of infused ANG II and an apparent attenuation of vascular responsiveness as in fetal sheep (24). In the present study, we examined the activity of the RAS and ANG II metabolism in conscious sheep in the first postnatal month. We observed 1) increased basal circulating levels of ANG II compared with the adult and a gradual decrease as MAP increased, 2) stable vascular responsiveness to infused ANG II after birth that does not reflect changes in $\mathrm{MCR}_{\mathrm{ANG}}$, and 3) persistent increase in PRA after birth, suggesting enhancement of RAS activity. Thus, $\mathrm{MCR}_{\text {ANG II }}$ does not explain the stable responses to infused $\mathrm{ANG}$ II, and persistent postnatal $\mathrm{AT}_{2} \mathrm{R}$ expression in peripheral VSM may protect the newborn from the hypertensive effects of excessive ANG II synthesis after birth $(9,10)$.

The increase in basal MAP immediately after birth is largely due to removal of the low resistance placental circulation, which accounts for $40 \%$ of cardiac output (32) and maintenance of a high cardiac output (33). In fetal sheep, the RAS was thought to regulate MAP by increasing PVR (4).
However, Kaiser et al. (11) reported that ANG II did not alter PVR in term fetal sheep, but rather contributed to MAP primarily by increasing umbilicoplacental vascular resistance. This reflected the advanced maturation and expression of $\mathrm{AT}_{1} \mathrm{R}$ in umbilical artery VSM in contrast to peripheral VSM, which was functionally less mature and expressed $\mathrm{AT}_{2} \mathrm{R}$ $(9,10,22)$. The $\mathrm{AT}_{2} \mathrm{R}$ is persistently expressed in peripheral VSM of newborn sheep $(9,10)$. Moreover, as in fetal sheep (11), arterial ANG II infusions in the newborn hind limb do not elicit vasoconstrictor responses (17), suggesting that ANG II-induced pressor responses after birth occur through indirect mechanisms, e.g. release of AVP or catecholamines $(34,35)$. However, Wilson et al. (21) reported that increases in circulating ANG II after birth contributed to the increase in MAP. In contrast, we observed that circulating ANG II decreased in the first postnatal month and was inversely related to basal MAP. Our findings are strikingly similar to those of Broughton et al. (3), who also observed increased circulating ANG II-like activity after birth and a decrease from $839 \pm 96$ $\mathrm{pg} / \mathrm{mL}$ within $8 \mathrm{~h}$ to $315 \pm 49 \mathrm{pg} / \mathrm{mL}$ between $10 \mathrm{~h}$ and $7 \mathrm{~d}$ and $<111 \pm 15 \mathrm{pg} / \mathrm{mL}$ at $6-8 \mathrm{wk}$. We conclude that plasma ANG II is inversely related to the increase in postnatal MAP, making it unclear how ANG II contributes to postnatal blood pressure regulation.

In adult VSM, ANG II mediates its pressor effects by binding to $\mathrm{AT}_{1} \mathrm{R}(7,8,16)$. If $\mathrm{AT}_{1} \mathrm{R}$ predominated in $\mathrm{VSM}$ after birth, a marked increase in systemic MAP would have been expected followed by persistent hypertension because of the higher levels of circulating ANG II observed by us and Broughton et al. (3). This does not occur, suggesting an immature receptor signaling mechanism in newborn VSM, incomplete biochemical development of VSM contractile function (22,36), or enhanced vascular synthesis of an ANG II antagonist, e.g. prostacycline or nitric oxide (37). Alternatively, persistent expression of $\mathrm{AT}_{2} \mathrm{R}$, which does not elicit contraction responses, in neonatal VSM could explain why MAP was not higher. This is supported by observations that $\mathrm{AT}_{1} \mathrm{R}$ binding in newborn VSM does not occur until $>2 \mathrm{wk}$ postnatally, and a complete switch to $\mathrm{AT}_{1} \mathrm{R}$ occurs after 3 mo postnatally (9). The increase in $\mathrm{AT}_{1} \mathrm{R}$ binding (9) and expression (10), however, parallels the increase in postnatal ovine MAP $(17,18)$. Because this is associated with decreased circulating ANG II, it is intriguing to consider that the decrease in plasma ANG II contributes to the increase in $\mathrm{AT}_{1} \mathrm{R}$ expression or receptor avidity in newborn VSM (38); this has not been studied. Although plasma ANG II decreased $75 \%$ in the first month, levels remained fourfold greater than adult values, $40 \mathrm{pg} / \mathrm{mL}(24,25,27)$. Thus, it remains unclear why basal MAP is not higher.

Before birth, $\mathrm{MCR}_{\mathrm{ANG}}$ II $700 \mathrm{~mL} / \mathrm{min} \cdot \mathrm{kg}(24,39)$, PRA is $>10 \mathrm{ng} / \mathrm{mL} \cdot \mathrm{h}$ (Fig. 5), and plasma ANG II is $40-70 \mathrm{pg} / \mathrm{mL}$, demonstrating enhanced activity of the fetal RAS and high ANG II production. The placental vascular bed accounts for 85\%-90\% of fetal ANG II clearance (24). Thus, the marked elevation in circulating ANG II immediately after birth $(1,3)$ reflects removal of the placenta and persistence of the high ANG II synthesis necessary to maintain fetal plasma ANG II. If placental clearance accounts of $>85 \%$ of fetal $\mathrm{MCR}_{\mathrm{ANG}}$ II' 


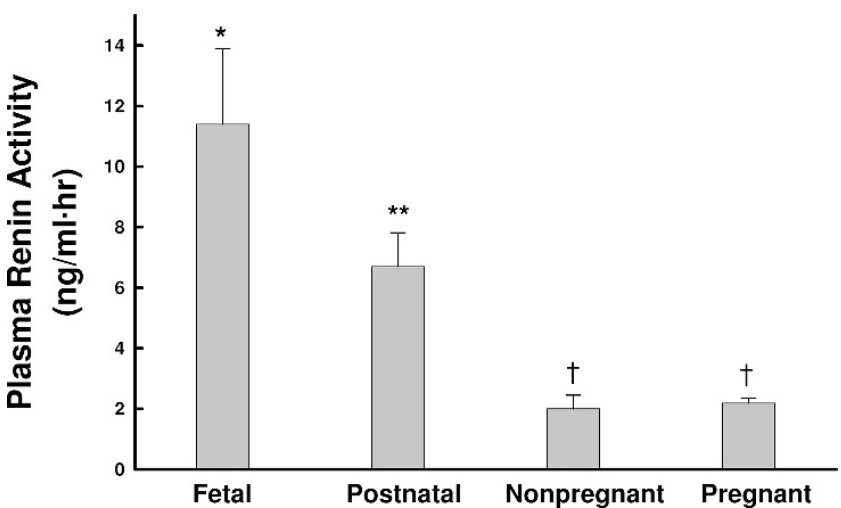

Figure 5. Comparison of arterial PRA in fetal $(n=5)$, newborn $(n=15)$, nonpregnant $(n=13)$, and pregnant $(n=6)$ sheep. Different symbols represent group differences at $p<0.001$, ANOVA. Values for fetal and adult sheep extracted from Kaiser et al. (11) and Matsuura et al. (28), respectively.

nonplacental clearance is $100 \mathrm{~mL} / \mathrm{min} \cdot \mathrm{kg}$. Notably, MCR was $115 \mathrm{~mL} / \mathrm{min} \cdot \mathrm{kg}$ postnatally, resembling values in adult women and sheep $(25,27)$. However, unlike the fetus and adult, the MCR increased with the higher ANG II dose, suggesting that this may be a mechanism for regulating circulating ANG II levels. Thus, we demonstrate for the first time that nonplacental ANG II metabolism is similar in the developing animal and adult, increased plasma ANG II at birth reflects an increased production rate consistent with PRA values three times greater than adult sheep (Fig. 5), and $\mathrm{MCR}_{\mathrm{ANG} \mathrm{II}}$ in the neonate is concentration dependent. We also provide evidence that the $\mathrm{MCR}_{\mathrm{ANG}}$ II is not responsible for the stable vascular responses to infused ANG II in newborn sheep $(17,21)$. Therefore, other mechanisms, not yet determined, are involved $(37,40)$.

ANG II is synthesized from ANG I, which is liberated by the action of renin on angiotensinogen. ANG II normally feeds back to inhibit renin secretion by a direct action on juxtaglomerular cells in the kidney via $\mathrm{AT}_{1} \mathrm{R}$, regulating circulating ANG II by a negative feedback mechanism that modifies ANG I levels. Thus, an inverse correlation between plasma ANG II and PRA normally exists $(41,42)$. In this study, basal PRA remained increased, although plasma ANG II was markedly increased. Thus, the negative feedback mechanism was not intact or the ANG II concentration required for activation was up-regulated (43-45). As in fetal and adult sheep $(11,24,25)$, acute elevations in ANG II decreased PRA, demonstrating an intact feedback mechanism. The persistent increase in PRA, despite increased ANG II levels, suggests RAS up-regulation before and after birth, resulting in an increased set point and attenuated feedback mechanism. This is consistent with previous observations of decreased pressor responses to infused ANG II when PRA is increased (46). Although PRA decreases with increasing age (Fig. 5), this occurs after the first postnatal month. Further, it is unclear why postnatal PRA remains increased and whether angiotensinogen or renin is also increased.

In this study, increased circulating ANG II and PRA persisted in the first postnatal month, demonstrating increased RAS activity. There also was an $83 \%$ decrease in MCR after birth, achieving values resembling fetal and adult non- placental clearance. Although PRA was increased and appeared unresponsive to increased circulating ANG II, the negative feedback mechanism was intact, suggesting upregulation of the set point, which allows enhanced ANG II synthesis, but the purpose is unclear. We suggest for the first time that persistent $\mathrm{AT}_{2} \mathrm{R}$ expression in newborn $\operatorname{VSM}(9,10)$ prevents the hypertensive effects of increased ANG II and may also attenuate vasoconstrictor effects by emerging $\mathrm{AT}_{1} \mathrm{R}(15)$. These data provide new insights into the RAS during development and its role in blood pressure regulation. Further studies are needed to clarify the role of the RAS during development.

Acknowledgments. Dr. Velaphi is presently Head of Neonatology at Chris Hani Baragwanath Hospital, University of Witwatersrand, Johannesburg, South Africa.

\section{REFERENCES}

1. Davidson D 1987 Circulating vasoactive substances and hemodynamic adjustments at birth in lambs. J Appl Physiol 63:676-684

2. Segar JL 1997 Ontogeny of the arterial and cardiopulmonary baroreflex during fetal and postnatal life. Am J Physiol 273:R457-R471

3. Broughton Pipkin F, Kirkpatrick SM, Lumbers ER, Mott JC 1974 Renin and angiotensin-like levels in fetal, newborn and adult sheep. J Physiol 241:575-588

4. Iwamoto HS, Rudolph AM 1979 Effects of endogenous angiotensin II on the fetal circulation. J Dev Physiol 1:283-293

5. Siegel SR, Fisher DA 1979 The effects of angiotensin blockade and nephrectomy on the renin-angiotensin-aldosterone system in the newborn lamb. Pediatr Res 13:603605

6. Mathai ML, Pennington GL, Mckinley MJ 1997 The effect of angiotensin AT receptor blockade in the brain on the maintenance of blood pressure during haemorrhage in sheep. Acta Physiol Scand 161:495-502

7. Bottari SP, Gasparo M, Steckelings UM, Levens NR 1993 Angiotensin II receptor subtypes: characterization, signaling mechanisms, and possible physiological implications. Front Neuroendocrinol 14:123-171

8. Cox BE, Rosenfeld CR, Kalinyak JE, Magness RR, Shaul PW 1996 Tissue specific expression of vascular smooth muscle angiotensin II receptor subtypes during ovine pregnancy. Am J Physiol 271:H212-H221

9. Cox BE, Rosenfeld CR 1999 Ontogeny of vascular angiotensin II receptor subtype expression in ovine development. Pediatr Res 45:414-424

10. Cox BE, Liu X. Fluharty SJ, Rosenfeld CR 2005 Vessel specific regulation of angiotensin II receptor subtypes during ovine development. Pediatr Res 57:124-132

11. Kaiser JR, Cox BE, Roy TA, Rosenfeld CR 1998 Differential development of umbilical and systemic arteries. I. ANG II receptor subtype expression. Am J Physiol 274:R797-R807

12. Owens GK, Kumar MS, Wamhoff BR 2004 Molecular regulation of vascular smooth muscle cell differentiation in development and disease. Physiol Rev 84:767-801

13. Yoshida T, Owens GK 2005 Molecular determinants of vascular smooth muscle cell diversity. Circ Res 96:280-291

14. Yamada H, Akishita M, Ito M, Tamura K, Daviet L, Lehtonen JY, Dzau VJ, Horiuchi M $1999 \mathrm{AT}_{2}$ receptor and vascular smooth muscle differentiation in vascular development. Hypertension 33:1414-1419

15. McMullen JR, Gibson KJ, Lumbers ER, Wu J 1999 Interactions between AT1 and AT2 receptors in uterine arteries from pregnant ewes. Eur J Pharmacol 378:195-202

16. Cox BE, Ipson MA, Shaul PW, Kamm KE, Rosenfeld CR 1993 Myometrial angiotensin II receptor subtypes change during ovine pregnancy. J Clin Invest 92:2240-2248

17. Velaphi SC, Roy T, DeSpain K, Rosenfeld CR 2002 Differential responses to systemic and local angiotensin II infusions in conscious postnatal sheep. Pediatr Res 52:333-341

18. Velaphi SC, Roy T, DeSpain K, Rosenfeld CR 2005 Effects of systemic and local phenylephrine and arginine vasopressin infusions in conscious postnatal sheep Pediatr Res 58:58-65

19. Engle WD 2001 Blood pressure in the very low birth weight neonate. Early Hum Dev 62:97-130

20. Zubrow AB, Hulman S, Kushner H, Falkner B 1995 Determinants of blood pressure in infants admitted to neonatal intensive care units: a prospective multicenter study. J Perinatol 15:470-479

21. Wilson TA, Kaiser DL, Wright EM Jr, Ortt EM, Freedlender AE, Peach MJ, Carey RM 1981 Importance of plasma angiotensin concentrations in a comparative study of responses to angiotensin in the maturing newborn lamb. Hypertension 3:II-18-24

22. Arens Y, Chapados R, Cox BE, Kamm KE, Rosenfeld CR 1998 Differential development of umbilical and systemic arteries. II. Contractile proteins. Am J Physiol 274:R1815-R1823

23. Yoshimura T, Magness RR, Rosenfeld CR 1990 Angiotensin II and $\alpha$-agonist I. Responses of ovine fetoplacental vasculature. Am J Physiol 259:H464-H472

24. Rosenfeld CR, Gresores A, Roy TA, Magness RR 1995 Comparison of ANG II in fetal and pregnant sheep: metabolic clearance and vascular sensitivity. Am J Physiol 268:E237-E247 
25. Naden RP, Coultrup S, Arant BS, Rosenfeld CR 1985 Metabolic clearance of angiotensin II in pregnant and nonpregnant sheep. Am J Physiol 249:E49-E55

26. Wiriyathian S, Porter JC, Naden RP, Rosenfeld CR 1983 Cardiovascular effects and clearance of arginine vasopressin in the fetal lamb. Am J Physiol 245:E24-E3

27. Magness RR, Cox K, Rosenfeld CR, Gant NF 1994 Angiotensin II metabolic clearance rate and pressor responses in nonpregnant and pregnant women. Am J Obstet Gynecol 171:668-679

28. Matsuura S, Naden RP, Gant NF Jr, Parker CR Jr, Rosenfeld CR 1981 Effect of volume expansion on pressor response to angiotensin II in pregnant ewes. Am J Physiol 240:H908-H913

29. DeVane GW, Porter JC 1980 An apparent stress-induced release of arginine vasopressin by human neonates. J Clin Endocrinol Metab 51:1412-1416

30. Wiriyathian S, Rosenfeld CR, Arant BS Jr, Porter JC, Faucher DJ, Engle WD 1986 Urinary arginine vasopressin: Pattern of excretion in the neonatal period. Pediatr Res 20:103-108

31. Eliot RJ, Klein AH, Glatz TH, Nathanielsz PW, Fisher DA 1981 Plasma norepinephrine, epinephrine, and dopamine concentrations in maternal and fetal sheep during spontaneous parturition and in premature sheep during cortisol-induced parturition. Endocrinology 108:1678-1682

32. Rudolph AM 1985 Distribution and regulation of blood flow in the fetal and neonatal lamb. Circ Res 57:811-821

33. Woods JR Jr, Dandelion A, Brinkman CR 3rd, Unwashed B, Assali NS 1978 Cardiac output changes during neonatal growth. Am J Physiol 234:H520-H524

34. Shi L, Guerra C, Yao J, Xu J 2004 Vasopressin Mechanism-mediated pressor responses caused by central angiotensin II in the ovine fetus. Pediatr Res 56:756-762

35. Shi L, Hu F, Morrissey P, Yao J, Xu Z 2003 Intravenous angiotensin induces brain c-fos expression and vasopressin release in the near-term ovine fetus. Am J Physiol Endocrinol Metab 285:E1216-E1222
36. Owens GK 1995 Regulation of vascular smooth muscle cells. Physiol Rev 75:487517

37. Yoshimura T, Rosenfeld CR, Magness RR 1991 Angiotensin II and $\alpha$-agonist III. In vitro fetal-maternal placental prostaglandins. Am J Physiol 260:E8-E13

38. Brunner HR, Chang P, Wallace R, Sealey JE, Laragh JH 1972 Angiotensin II vascular receptors: their avidity in relationship to sodium balance, the autonomic nervous system, and hypertension. J Clin Invest 51:58-72

39. Stanley JR, Giammattei CE, Sheikh AU, Green JL, Zehnder T, Rose JC 1997 Effects of chronic infusions of angiotensin II on renin and blood pressure in the lategestation fetal sheep. Am J Obstet Gynecol 176:931-937

40. Magness RR, Osei-Boaten K, Mitchell MD, Rosenfeld CR 1985 In vitro prostacyclin production by ovine uterine and systemic arteries. Effects of angiotensin II. J Clin Invest 76:2206-2212

41. Swales JD, Thurston H 1977 Plasma renin and angiotensin II measurement in hypertensive and normal subjects: correlation of basal and stimulated states. J Clin Endocrinol Metab 45:159-163

42. Kosunen KJ, Pakarinen A 1978 Correlations between plasma renin activity, angiotensin II and aldosterone. J Clin Endocrinol Metab 47:665-666

43. Catt KJ, Zimmett PZ, Cain MD, Cran E, Best JB, Coghlan JP 1971 Angiotensin II blood levels in human hypertension. Lancet 1:459-464

44. Mendelsohn FA, Johnston CI, Doyle AE, Scoggins BA, Denton DA, Coghlan JP 1972 Renin, angiotensin II and adrenal corticosteroid relationships during sodium deprivation and angiotensin infusion in normotensive and hypertensive man. Circ Res 31:728-739

45. Walker WG, Horvath JS, Moore MA, Whelton PK, Russell RP 1976 Relation between plasma rennin activity, angiotensin and aldosterone and blood pressure in mild untreated hypertension. Circ Res 38:470-476

46. Kaplan NM, Silah JG 1964 The effect of angiotensin II on the blood pressure in humans with hypertensive disease. J Clin Invest 43:659-669 